Provided for non-commercial research and education use. Not for reproduction, distribution or commercial use.

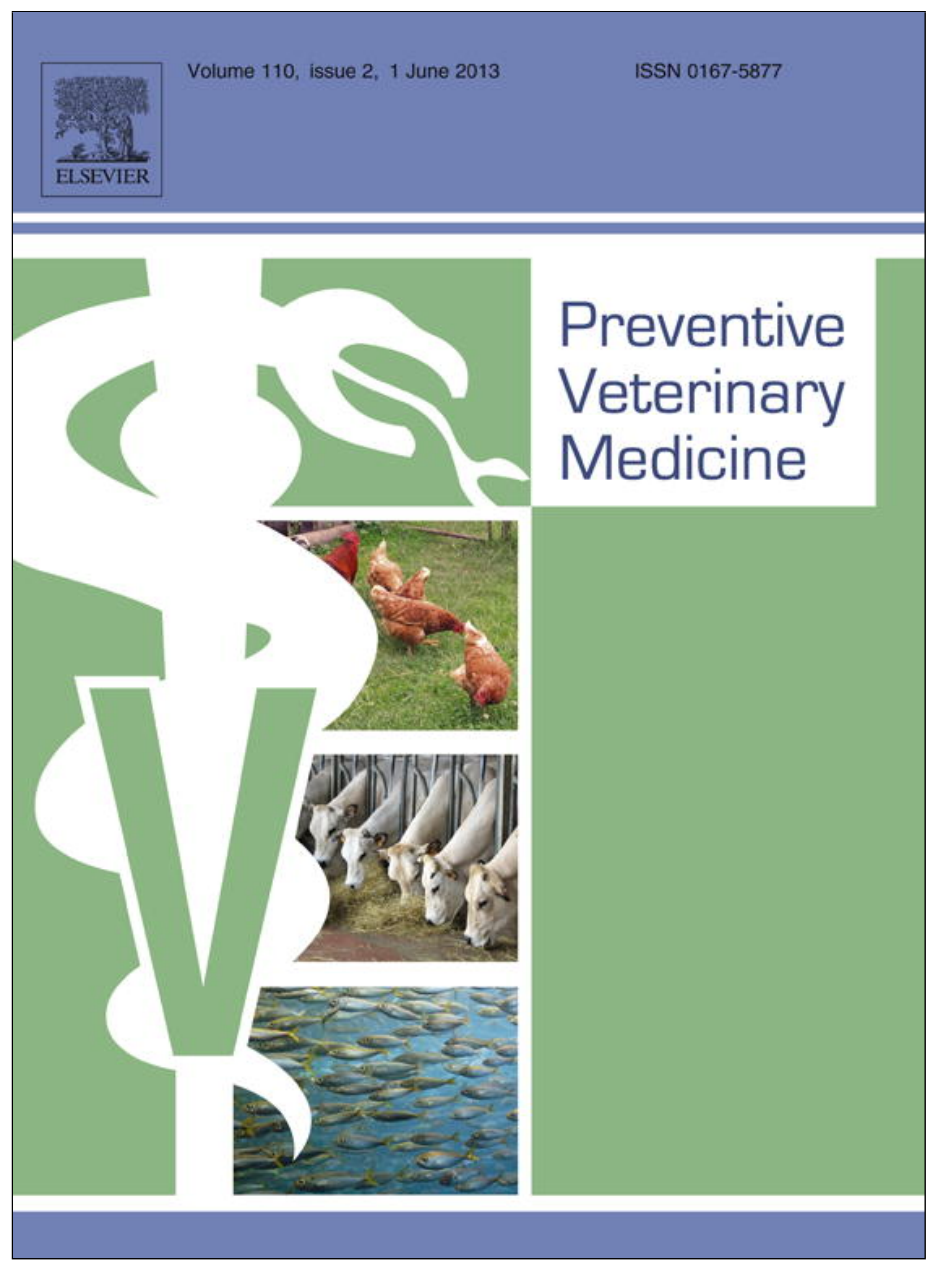

This article appeared in a journal published by Elsevier. The attached copy is furnished to the author for internal non-commercial research and education use, including for instruction at the authors institution and sharing with colleagues.

Other uses, including reproduction and distribution, or selling or licensing copies, or posting to personal, institutional or third party websites are prohibited.

In most cases authors are permitted to post their version of the article (e.g. in Word or Tex form) to their personal website or institutional repository. Authors requiring further information regarding Elsevier's archiving and manuscript policies are encouraged to visit:

http://www.elsevier.com/authorsrights 


\title{
Bayesian estimation of true prevalence, sensitivity and specificity of indirect ELISA, Rose Bengal Test and Slow Agglutination Test for the diagnosis of brucellosis in sheep and goats in Bangladesh
}

\author{
A.K.M. Anisur Rahman a,b,c,*, Claude Saegerman ${ }^{\mathrm{b}}$, Dirk Berkvens ${ }^{\mathrm{c}}$, David Fretin ${ }^{\mathrm{d}}$, \\ Md. Osman Gani ${ }^{\mathrm{e}}$, Md. Ershaduzzaman ${ }^{\mathrm{e}}$, Muzahed Uddin Ahmed ${ }^{\mathrm{a}}$, Abatih Emmanuel ${ }^{\mathrm{c}}$ \\ a Department of Medicine, Bangladesh Agricultural University, Mymensingh 2202, Bangladesh \\ ${ }^{\mathrm{b}}$ Research Unit of Epidemiology and Risk Analysis Applied to the Veterinary Sciences (UREAR), Department of Infectious and Parasitic Diseases, \\ Faculty of Veterinary Medicine, University of Liège, Liège, Belgium \\ c Unit of Epidemiology, Department of Biomedical Sciences, Institute of Tropical Medicine, Antwerpen, Belgium \\ d Department of Bacteriology and Immunology, Veterinary and Agrochemical Research Centre, Brussels, Belgium \\ e Goat and Sheep Production Research Division, Bangladesh Livestock Research Institute, Savar, Dhaka 1341, Bangladesh
}

\section{A R T I C L E I N F O}

\section{Article history:}

Received 14 May 2012

Received in revised form

29 November 2012

Accepted 30 November 2012

\section{Keywords:}

Bayesian model

Small ruminants

Brucellosis

Diagnostic tests

Sensitivity

Specificity

\begin{abstract}
A B S T R A C T
The true prevalence of brucellosis and diagnostic test characteristics of three conditionally dependent serological tests were estimated using the Bayesian approach in goats and sheep populations of Bangladesh. Serum samples from a random selection of 636 goats and 1044 sheep were tested in parallel by indirect ELISA (iELISA), Rose Bengal Test (RBT) and Slow Agglutination Test (SAT). The true prevalence of brucellosis in goats and sheep were estimated as $1 \%$ (95\% credibility interval (CrI): $0.7-1.8$ ) and 1.2\% (95\% CrI: 0.6-2.2) respectively. The sensitivity of iELISA was $92.9 \%$ in goats and $92.0 \%$ in sheep with corresponding specificities of $96.5 \%$ and $99.5 \%$ respectively. The sensitivity and specificity estimates of RBT were $80.2 \%$ and $99.6 \%$ in goats and $82.8 \%$ and $98.3 \%$ in sheep. The sensitivity and specificity of SAT were $57.1 \%$ and $99.3 \%$ in goats and $72.0 \%$ and $98.6 \%$ in sheep. In this study, three conditionally dependent serological tests for the diagnosis of small ruminant brucellosis in Bangladesh were validated. Considerable conditional dependence between IELISA and RBT and between RBT and SAT was observed among sheep. The influence of the priors on the model fit and estimated parameter values was checked using sensitivity analysis. In multiple test validation, conditional dependence should not be ignored when the tests are in fact conditionally dependent.
\end{abstract}

(c) 2012 Elsevier B.V. All rights reserved.

\section{Introduction}

Brucella melitensis, primarily responsible for brucellosis in sheep and goats is by far, the most important zoonotic agent among Brucella spp. (Anonymous, 1986; SolorioRivera et al., 2007). Brucellosis in sheep and goats is rarely

\footnotetext{
* Corresponding author at: Bangladesh Agricultural University, Department of Medicine, BAU Campus, Mymensingh 2202, Bangladesh. Tel.: +8801713409196; fax: +8809161510.

E-mail address: ranisur@itg.be (A.K.M.A. Rahman).
}

caused by Brucella abortus and Brucella suis (EC, 2001). Brucella ovis causes epididymitis in rams but rarely causes abortion in ewes (Van Tonder et al., 1994) and does not cause disease in humans. In the majority of industrialized countries, bovine brucellosis has been eradicated or controlled. However, small ruminant brucellosis remains a problem in some of these countries as well as in all developing countries. Basically, brucellosis is almost always present where small ruminants are kept (Godfroid et al., 2005; Franco et al., 2007).

There are about 36.5 million goats and 1.69 million sheep representing more than $57 \%$ of the total livestock 
of Bangladesh. About $85 \%$ of rural households own animals and $75 \%$ of the population rely on livestock to some extent for their livelihood (Anonymous, 2005; BBS, 2004). More than $98 \%$ of goats are owned by the small, marginal and landless farmers in the villages. Their small body size and easy management especially by feeding on road side grasses, tree leaves and kitchen vegetable wastes i.e. investing practically nothing, attracts poor women and children to small ruminant rearing (Amin, 2006). A good proportion of humans in Bangladesh have very close contacts with small ruminants and direct contact with animals is the principal route of brucellosis transmission. The epidemiological understanding of small ruminant brucellosis is in a very preliminary stage in Bangladesh. The estimated seroprevalence of brucellosis in Bangladesh based on previous studies ranges from $0.7 \%$ to $14.6 \%$ in goats (Mustafa, 1984; Rahman et al., 1988, 2011a,b) and 0 to $4.8 \%$ in sheep (Mustafa, 1984; Amin, 2003; Uddin, 2006; Rahman et al., 2011a,b).

The serological tests used in previous studies were the Rose Bengal Test (RBT), Standard Tube Agglutination Test, ELISA or Plate Agglutination Test. None of the aforementioned tests are perfect. So, the prevalence reported using these tests are not true prevalence due to misclassification of some of the tested animals. Moreover, the performance of these tests has not been validated in naturally infected small ruminants of Bangladesh. Tests are normally validated by comparing with the gold standard or perfect test. However, the gold standard for the diagnosis of brucellosis is isolation and identification of the organism (Alton et al., 1988; OIE, 2008) which is not easy to perform in a developing and resource-limited country like Bangladesh. In the absence of a gold standard, simultaneous estimation of true prevalence and diagnostic test characteristics can be performed successfully when applying multiple diagnostic tests to every individual subject, using a Bayesian approach which combines test results and external information (Berkvens et al., 2006; Adel et al., 2010; Praud et al., 2012).

An important consideration in the evaluation of multiple diagnostic tests is whether or not the tests can be assumed conditionally independent of each other given the true disease status. It has been demonstrated that the assumption of conditional independence may lead to biased estimates for test characteristics if in fact the tests are conditionally dependent (Vacek, 1985; Gardner et al., 2000). Since iELISA, RBT and SAT are based on the same biological process (Nielsen, 2002) i.e. detection of anti-Brucella-smooth-lipopolysaccharide (SLPS) antibodies, they can be considered to be conditionally dependent (Gardner et al., 2000). Therefore, the estimation procedures should be adjusted for the dependencies among the tests (Dendukuri and Joseph, 2001; Branscum et al., 2005). Few reports have been noted where authors considered test dependence in a multiple testing strategy for the diagnosis of porcine and bovine brucellosis (Ferris et al., 1995; Mainar-Jaime et al., 2005; Praud et al., 2012) but none was noted for the diagnosis of small ruminants brucellosis.

The aim of this study was to estimate the true prevalence of brucellosis in small ruminants of Bangladesh and to evaluate the performance of three conditionally dependent serological tests namely indirect ELISA, RBT and SAT using a Bayesian modeling approach.

\section{Materials and methods}

\subsection{Study and sampling design}

Livestock herds in Bangladesh are not identified regionally or centrally in the form of a data bank. To obtain random samples in this context a map digitization and herd selection procedure was followed in the Mymensingh district of Bangladesh. Out of a total of the 146 unions (sub Upa-Zilla) of Mymensingh district (consisting of several Upa-Zillas), 28 were randomly selected. Usually one geographical coordinate was randomly selected from each selected union and located by a hand held GPS reader. Livestock farmers within $0.5 \mathrm{~km}$ radius of the selected point were informed about the survey. All animals of the selected herds were sampled. Since there were very few sheep in Mymensingh district, blood samples were also collected from all other divisions of Bangladesh except in Khulna through the nationwide network of the Bangladesh Livestock Research Institute (BLRI) using the same sampling design scheme. The study area is shown in Fig. 1. The study was conducted initially between September 2007 and August 2008 and then between January 2010 and May 2010 additional sheep samples were collected. In addition, a pretested questionnaire designed to collect animal and herd level data during blood sampling was administered.

\subsection{Processing of blood samples}

About $4 \mathrm{ml}$ of blood was collected from each animal by jugular venipuncture with disposable needles and venoject tubes, labeled and transported to the laboratory on ice (after clotting) within $12 \mathrm{~h}$ of collection. Blood samples were kept in the refrigerator $\left(2-8{ }^{\circ} \mathrm{C}\right)$ in the laboratory and one day later sera were separated by centrifuging at $6000 \times g$ for $10 \mathrm{~min}$. Each serum was labeled to identify the animal and stored at $-20^{\circ} \mathrm{C}$. Blood samples collected from other districts were processed in respective districts and sera stored at $-20^{\circ} \mathrm{C}$ in regional BLRI field stations and conveniently transferred to the medicine department laboratory of Bangladesh Agricultural University (BAU). Each serum was divided into two tubes each containing about $1 \mathrm{ml}$ of serum. One aliquot was used for testing and the other was preserved in a serum bank.

\subsection{Serological tests}

All blood samples were tested in parallel by iELISA, RBT and SAT in the medicine department laboratory of BAU, Mymensingh, Bangladesh.

iELISA was performed according to Limet et al. (1988) using $B$. abortus biotype 1 (Weybridge 99) as antigen. The detail procedure was described in a previous paper by Rahman et al. (2012). The cut-off value for a positive result was defined at $2 \mathrm{U} / \mathrm{ml}$ of test serum for goats (Godfroid et al., 2002) and $6 \mathrm{U} / \mathrm{ml}$ of test serum for sheep (Pers. Comm. David Fretin). 


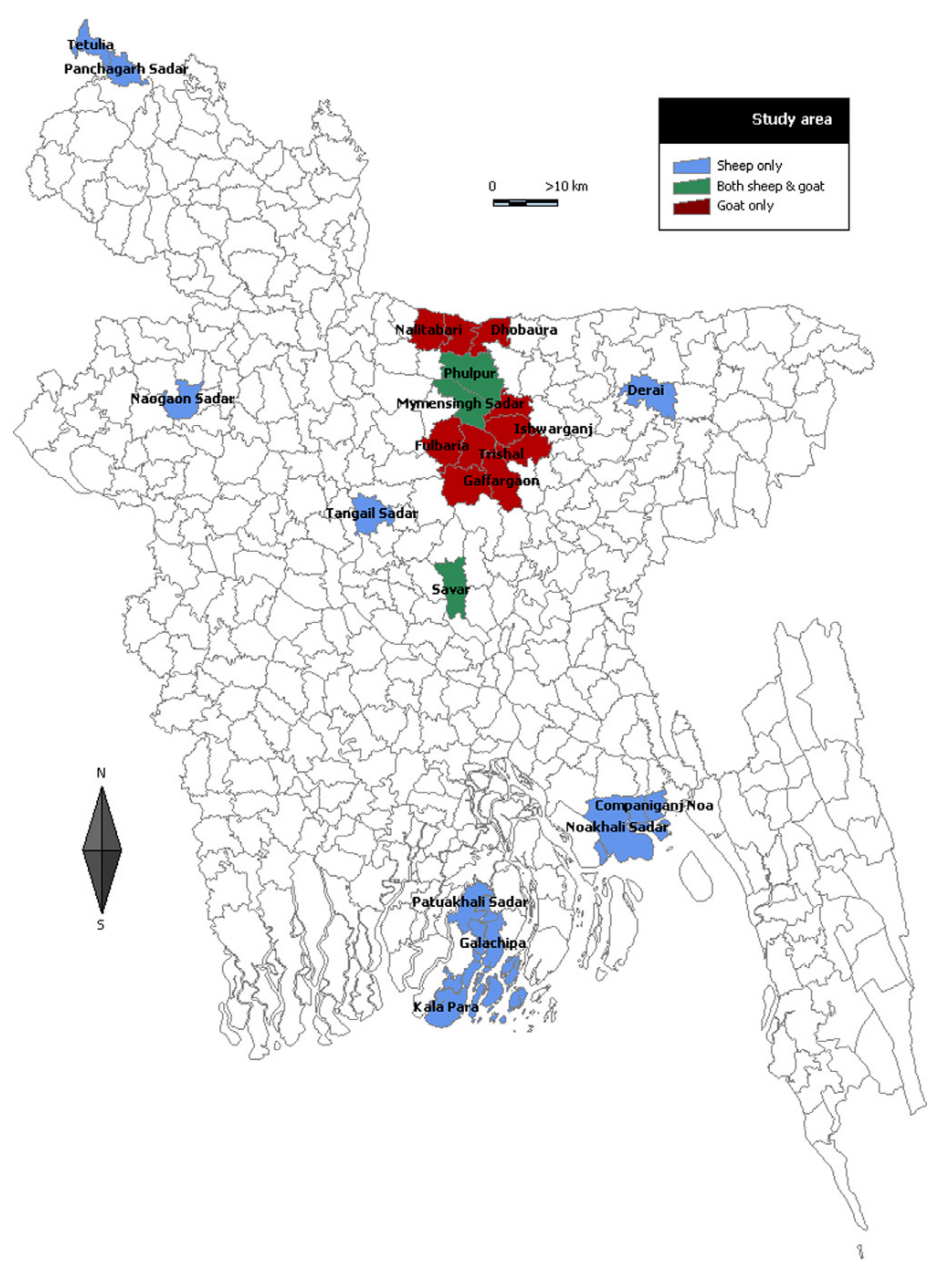

Fig. 1. Map of Bangladesh showing the study areas.

RBT was performed as described by Alton et al. (1988). Briefly, sufficient antigen, test sera, positive and negative control sera for a day's testing were removed from refrigeration and brought to room temperature $\left(22 \pm 4{ }^{\circ} \mathrm{C}\right)$. Equal volumes $(30 \mu \mathrm{l})$ of serum and antigen (concentrated suspension of $B$. abortus biotype 1 (Weybridge 99); Institut Pourquier, France) were mixed and rotated on a glass plate for $4 \mathrm{~min}$. The result was considered positive when agglutination was noticeable after this delay.

SAT was carried out with ethylenediaminetetraacetic acid (EDTA) as described by Garin et al. (1985). The antigen used was B. abortus biotype 1 (Weybridge 99) (Synbiotics Europe, France). One hundred and sixty eight microliter of SAW buffer in the first well and $100 \mu \mathrm{l}$ in the second and the third wells were added in 96-well microtiter plate. Thirty two microliter of serum was added in the first well (dilution 1/6.25). After proper mixing of diluent and serum, $100 \mu \mathrm{l}$ from the first well was transferred to the second well (1/12.5). In the same way $100 \mu \mathrm{l}$ was transferred from the second to the third well (dilution $1 / 25$ ) and $100 \mu \mathrm{l}$ discarded from the third well. Then in each well $100 \mu \mathrm{l}$ of standardized SAW antigen was added giving the serial serum dilutions of $1 / 12.5,1 / 25$ and $1 / 50$. The plates were agitated and incubated at $37^{\circ} \mathrm{C}$ for $20-24 \mathrm{~h}$. Reading was done on the basis of degree of agglutination and expressed in international units (IU). Any serum with an antibody titer greater than or equal to $30 \mathrm{IU} / \mathrm{ml}$, as prescribed by the EU (Shey-Njila et al., 2005), was considered positive.

\subsection{Statistical analysis}

\subsubsection{Model building}

A Bayesian latent class analysis was implemented in WinBUGS 1.4 (Spiegelhalter et al., 2003) and R 2.14.2 (R Foundation and Statistical Computing 2012) to estimate the prevalence, sensitivity and specificity of the three tests, using models developed by Branscum et al. (2005), Berkvens et al. (2006), Nérette et al. (2008) and Haley et al. (2011) separately for sheep and goats. In a three test scenario, 7 parameters need to be estimated by the multinominal model under the assumption of conditional independence namely; the prevalence, and the sensitivities and specificities of the three tests. However, under the assumption of conditional dependence, 6 additional parameters need to be estimated namely the conditional covariance between each pair of tests among infected and non-infected subjects. This model is in fact non-identifiable since the data only allows for seven parameters to be estimated. As none of the three tests is considered a gold standard test and the tests are not conditionally independent, constraints have to be imposed on a subset of the parameters in order to make the models identifiable 
(Branscum et al., 2005). To evaluate the goodness of fit of the models, the posterior predictive $p$-value, Deviance Information Criterion (DIC) (Spiegelhalter et al., 2002) and the number of effectively estimated parameters $(p D)$ (Berkvens et al., 2006) were used as calibrating parameters. Briefly, the DIC ensures that a parsimonious model is selected. It is calculated as DIC $=p D+D$ with $D$ the mean posterior deviance and $p D$ the number of parameters effectively estimated by the model. Models with a smaller DIC should be preferred to models with larger DIC. The posterior predictive $p$-value is a posterior predictive check that detects lack-of-fit of the model to the data. It is based on the difference between the deviance of the observations and the deviance of observations generated randomly from the currently fitted model and for models that provide adequate fit to the data, the value should be around 0.50. A posterior predictive $p$-value of 0.5 is the value that would be obtained if the distribution of the deviances based on the observed and simulated data sets overlapped perfectly (Kelly and Smith, 2011). The apparent prevalence for sheep in $2007 / 2008$ was $3.7 \%$ [18/482] (95\% credibility intervals (CrI): 2.2-5.8) and that in 2010 was 2.5\% [ 14/562] (95\% CrI: 1.4-4.1). Using the "prtesti" command in Stata 12.1, we observed that the difference between the two proportions was not statistically significant $(p$-value $=0.3015$ ) therefore data for the two phases were combined. different parameterizations of the model that assumed conditional dependence between tests (Branscum et al., 2005; Berkvens et al., 2006; Nérette et al., 2008). Jones et al. (2010) proposed that in the construction of conditional dependence models, mainly simple extensions of the conditional independence model should be considered. Essentially, in the first set of simple parameterizations, the conditional dependence between iELISA and RBT, between iELISA and SAT and between RBT and SAT were each added in turn to the conditional independence model. In addition, three models were constructed with conditional dependence between the pairs: iELISA-RBT and iELISA-SAT, iELISA-RBT and RBT-SAT and between iELISA-SAT and RBT-SAT respectively (Nérette et al., 2008). Finally a model with conditional dependence among all the three tests was considered (all pairs inclusive) separately among infected and non-infected individuals and also among infected and non-infected animals combined. The models for both goats and sheep along with their corresponding parameters are presented in Table 3.

Letting $\pi$ to be the true prevalence, $T_{1}, T_{2}$ and $T_{3}$ to represent the test outcomes for iELISA, RBT and SAT respectively, with positive test outcomes denoted by 1 ( or + ), negative test outcomes by 0 (or - ), and sensitivities and specificities by Se and $S p$ respectively, the expected cell probabilities $(p)$ based on these three tests under the assumption of conditional dependence are given as follows:

$$
\begin{aligned}
& p(111)=P\left(T_{1}^{+}, T_{2}^{+}, T_{3}^{+}\right)=\pi\left(\mathrm{Se}_{1} \mathrm{Se}_{2} \mathrm{Se}_{3}+\mathrm{Se}_{1} a_{23}+\mathrm{Se}_{2} a_{13}+\mathrm{Se}_{3} a_{12}\right)+ \\
& (1-\pi)\left(\left(1-\mathrm{Sp}_{1}\right)\left(1-\mathrm{Sp}_{2}\right)\left(1-\mathrm{Sp}_{3}\right)+\left(1-\mathrm{Sp}_{1}\right) b_{23}+\left(1-\mathrm{Sp}_{2}\right) b_{13}+\left(1-\mathrm{Sp}_{3}\right) b_{12}\right) \\
& p(110)=P\left(T_{1}^{+}, T_{2}^{+}, T_{3}^{-}\right)=\pi\left(\mathrm{Se}_{1} \mathrm{Se}_{2}\left(1-\mathrm{Se}_{3}\right)-\mathrm{Se}_{1} a_{23}-\mathrm{Se}_{2} a_{13}+\left(1-\mathrm{Se}_{3}\right) a_{12}\right)+ \\
& (1-\pi)\left(\left(1-\mathrm{Sp}_{1}\right)\left(1-\mathrm{Sp}_{2}\right) \mathrm{Sp}_{3}-\left(1-\mathrm{Sp}_{1}\right) b_{23}-\left(1-\mathrm{Sp}_{2}\right) b_{13}+\mathrm{Sp}_{3} b_{12}\right) \\
& p(101)=P\left(T_{1}^{+}, T_{2}^{-}, T_{3}^{+}\right)=\pi\left(\mathrm{Se}_{1}\left(1-\mathrm{Se}_{2}\right) \mathrm{Se}_{3}-\mathrm{Se}_{1} a_{23}-\left(1-\mathrm{Se}_{2}\right) a_{13}-\mathrm{Se}_{3} a_{12}\right)+ \\
& (1-\pi)\left(\left(1-\mathrm{Sp}_{1}\right)\left(1-\mathrm{Sp}_{2}\right) \mathrm{Sp}_{3}-\left(1-\mathrm{Sp}_{1}\right) b_{23}-\left(1-\mathrm{Sp}_{2}\right) b_{13}+\mathrm{Sp}_{3} b_{12}\right) \\
& p(100)=P\left(T_{1}^{+}, T_{2}^{-}, T_{3}^{-}\right)=\pi\left(\mathrm{Se}_{1}\left(1-\mathrm{Se}_{2}\right)\left(1-\mathrm{Se}_{3}\right)+\mathrm{Se}_{1} a_{23}-\left(1-\mathrm{Se}_{2}\right) a_{13}-\left(1-\mathrm{Se}_{3}\right) a_{12}\right) \\
& +(1-\pi)\left(\left(1-\mathrm{Sp}_{1}\right) \mathrm{Sp}_{2} \mathrm{Sp}_{3}-\left(1-\mathrm{Sp}_{1}\right) b_{23}-\mathrm{Sp}_{2} b_{13}-\mathrm{Sp}_{3} b_{12}\right) \\
& p(011)=P\left(T_{1}^{-}, T_{2}^{+}, T_{3}^{+}\right)=\pi\left(\left(1-\mathrm{Se}_{1}\right) \mathrm{Se}_{2} \mathrm{Se}_{3}+\left(1-\mathrm{Se}_{1}\right) a_{23}-\mathrm{Se}_{2} a_{13}-\mathrm{Se}_{3} a_{12}\right)+ \\
& (1-\pi)\left(\mathrm{Sp}_{1}\left(1-\mathrm{Sp}_{2}\right)\left(1-\mathrm{Sp}_{3}\right)+\mathrm{Sp}_{1} b_{23}-\left(1-\mathrm{Sp}_{2}\right) b_{13}-\left(1-\mathrm{Sp}_{3}\right) b_{12}\right) \\
& p(010)=P\left(T_{1}^{-}, T_{2}^{+}, T_{3}^{-}\right)=\pi\left(\left(1-\mathrm{Se}_{1}\right) \mathrm{Se}_{3}\left(1-\mathrm{Se}_{3}\right)-\left(1-\mathrm{Se}_{1}\right) a_{23}-\mathrm{Se}_{2} a_{13}-\left(1-\mathrm{Se}_{3}\right) a_{12}\right) \\
& +(1-\pi)\left(\mathrm{Sp}_{1}\left(1-\mathrm{Sp}_{2}\right) \mathrm{Sp}_{3}-\mathrm{Sp}_{1} b_{23}+\left(1-\mathrm{Sp}_{2}\right) b_{13}-\mathrm{Sp}_{3} b_{12}\right) \\
& p(001)=P\left(T_{1}^{-}, T_{2}^{-}, T_{3}^{-}\right)=\pi\left(\left(1-\mathrm{Se}_{1}\right)\left(1-\mathrm{Se}_{3}\right) \mathrm{Se}_{3}-\left(1-\mathrm{Se}_{1}\right) a_{23}-\left(1-\mathrm{Se}_{2}\right) * a_{13}+\mathrm{Se}_{3} * a_{12}\right) \\
& +(1-\pi)\left(\mathrm{Sp}_{1} \mathrm{Sp}_{2}\left(1-\mathrm{Sp}_{3}\right)+\mathrm{Sp}_{1} b_{23}+\mathrm{Sp}_{2} * b_{13}+\left(1-\mathrm{Sp}_{3}\right) * b_{12}\right) \\
& p(000)=P\left(T_{1}^{-}, T_{2}^{-}, T_{3}^{-}\right)=\pi\left(\left(1-\mathrm{Se}_{1}\right)\left(1-\mathrm{Se}_{3}\right)\left(1-\mathrm{Se}_{3}\right)+\left(1-\mathrm{Se}_{1}\right) a_{23}+\left(1-\mathrm{Se}_{2}\right) a_{13}+\mathrm{Se}_{3} * a_{12}\right) \\
& \left.+\left(1-\mathrm{Se}_{3}\right) a_{12}\right)+(1-\pi)\left(\mathrm{Sp}_{1} \mathrm{Sp}_{2} \mathrm{Sp}_{3}+\mathrm{Sp}_{1} b_{23}+\mathrm{Sp}_{2} * b_{13}+\left(\mathrm{Sp}_{3}\right) * b_{12}\right)
\end{aligned}
$$

Representing the conditional covariance between pairs of tests among infected animals by $a$ and among the non-infected population by $b$ (Table 5 ), median posterior estimates were obtained along with their 95\% CrI. In addition, conditional correlations were computed as described in Georgiadis et al. (2003), Haley et al. (2011) and Branscum et al. (2005). According to Georgiadis et al. (2003), when the conditional correlations are low $(\leq 0.2)$, the estimates

\subsubsection{Modeling conditional dependence}

Using the model that assumes conditional independence among the three tests given the true disease status of individuals as the baseline model, conditional dependence between each pair of tests was estimated using 
Table 1

Sources of priors used for estimation of diagnostic test characteristics for brucellosis in goats and sheep in Bangladesh.

\begin{tabular}{|c|c|c|c|c|c|c|c|}
\hline \multirow[t]{2}{*}{ References } & \multirow[t]{2}{*}{ Species } & \multicolumn{2}{|l|}{ iELISA } & \multicolumn{2}{|l|}{ RBT } & \multicolumn{2}{|l|}{ SAT } \\
\hline & & Se & Sp & Se & Sp & Se & $\mathrm{Sp}$ \\
\hline Blasco et al. (1994) & SG & 1 & 1 & $91.8-92.5$ & 1 & & \\
\hline Baum et al. (1995) & SG & & & & & $90.3-96.7$ & $97.7-1$ \\
\hline Abuharfeil and Abo-Shehada (1998) & $\mathrm{S}$ & $66.5-78.7$ & & $34.4-47.8$ & & & \\
\hline Burriel et al. (2004) & SG & $88.1-96.7$ & $94.7-99.2$ & & & & \\
\hline Nielsen et al. (2004) & SG & $82.1-96.6$ & $96.4-98.4$ & $64.7-85.3$ & $99.0-99.9$ & & \\
\hline Nielsen et al. (2005) & $G$ & $94.5-97.5$ & $99.3-99.9$ & & & & \\
\hline Minas et al. (2005) & $\mathrm{S}$ & $92.7-96.3$ & $1-1$ & $67.0-74.1$ & $99.3-1$ & & \\
\hline EFSA-Q-2006 & SG & $94.5-95.8$ & $99.1-99.3$ & $91.6-93.4$ & $99.8-1$ & & \\
\hline Minas et al. (2008) & SG & $97.6-98.8$ & $99.8-1$ & $74.0-77.7$ & $99.5-99.9$ & & \\
\hline Ramirez-Pfeiffer et al. (2008) & SG & & & $76.5-85.2$ & $61.9-74.4$ & & \\
\hline Gupta et al. (2010) & $\mathrm{G}$ & & & & & $30.1-79.2$ & $50.6-90.4$ \\
\hline
\end{tabular}

SG: sheep and goat; G: goat only; S: sheep only; iELISA: indirect ELISA; RBT: Rose Bengal Test; SAT: Slow Agglutination Test; Se: sensitivity; Sp: specificity.

of the conditional dependence and independence models are similar whereas when the correlations are high $(>0.2)$ the conditional dependence model should be considered.

All models were compared using the DIC and posterior predictive $p$-values. To be considered significantly different, the reduction in DIC between any two models should be more than 3 units (Spiegelhalter et al., 2002; Kostoulas et al., 2006; Nérette et al., 2008). In situations where the difference in DIC was smaller than 3 units, the models were assumed to be similar and selection was based on parsimony (the smaller the number of effective parameters estimated $(p D)$ the better) (Spiegelhalter et al., 2002).

\subsection{Prior distributions for parameters}

Based on a review of the literature, limited information was available regarding the true prevalence and test sensitivities and specificities for brucellosis among small ruminants in Bangladesh. Therefore, prior information from other similar studies were used. A very important source of prior information was the EFSA report of 2006 (EFSA-Q-2006) in which a thorough meta-analytic approach was used to estimate priors of Se and Sp for RBT, iELISA and SAT in sheep and goats. Based on several studies obtained from the literature, a meta-analysis was performed using "metandi" in Stata 12.1 (Harbord and Whiting, 2009). To perform metandi, a minimum of four studies is required. However, for SAT, only two studies were available therefore, the meta-analysis was performed for RBT and iELISA. In addition, mentandi requires that the number of true positives, true negatives, false positives and false negatives be know for each study. This was not available for the meta-analytic study based on the EFSA report so the priors were combined: the lowest limit was used as the lower bound and the higher value as the upper bound in uniform distributions. The same set of priors for the sensitivity and specificity were used both for sheep and goats data. The prior interval estimates used in uniform distributions for the Se and Sp were $(0.870,0.986)$ and $(0.962$, $1.00)$ for iELISA $(0.670,0.934)$ and $(0.915,1.00)$ for RBT and $(0.301,0.967)$ and $(0.977,1)$ for SAT respectively.

The priors used for the prevalence of brucellosis in goats and sheep in Bangladesh were based on local prevalence reports $0.7-14.6 \%$ in goats (Mustafa, 1984; Rahman et al., 1988, 2011a,b) and 0-4.8\% in sheep (Mustafa, 1984;
Amin, 2003; Uddin, 2006; Rahman et al., 2011a,b). The prior sources for sensitivities and specificities of the three serological tests used for the Bayesian analysis in this study are summarized in Table 1. Prior information on the 8 covariance parameters ( 4 for infected and 4 for the non-infected individuals) were not available so initial values were generated in R 2.14.2 based on the range of possible values of the sensitivities and specificities listed in Table 1 (see Appendix B).

\subsection{Model diagnostics}

All models were run using three chains, a burn-in period of 50,000 iterations and another 100,000 iterations to obtain the posterior estimates. Trace plots were used to explore how fast the chain explores the posterior distribution (Ntzoufras, 2011). A more formal test for convergence, the Brooks, Gelman and Rubin convergence statistic was used to assess model convergence (Gelman and Rubin, 1992). The WinBUGS codes used are presented in Appendices A and B.

\subsection{Sensitivity analyses of selected models}

The influence of the prior information on the estimates of the diagnostic test characteristics were verified using sensitivity analysis (Branscum et al., 2005; Kostoulas et al., 2006; Praud et al., 2012). This was done by using standard uniform priors and slight perturbations (in steps of $10 \%$ or 15\%) of the prior intervals (Haley et al., 2011). The following sets of priors were considered:

- Uniform prior (UP) for prevalence (Pr) and informative priors (IP) for sensitivities (Se) and Specificities (Sp)

- UP for Pr and for Se and IP for Sp

- UP for Pr and for Sp and IP for Se

- IP for Pr and UP for Se and Sp

- IP for Pr and for Se and UP for Sp

- IP for Pr and for Sp and UP Se

- Perturbations of the prior interval

For each set of alternative prior distributions considered for the model parameters, the model was run with the same number of chains and similar diagnostics were performed. 
Table 2

Cross-classified test results for brucellosis in goats and sheep of Bangladesh based on iELISA, RBT, and SAT.

\begin{tabular}{lllll}
\hline iELISA & RBT & SAT & Goat & Sheep \\
\hline 1 & 1 & 1 & 2 & 8 \\
1 & 1 & 0 & 1 & 3 \\
1 & 0 & 1 & 0 & 0 \\
1 & 0 & 0 & 29 & 5 \\
0 & 1 & 1 & 0 & 9 \\
0 & 1 & 0 & 2 & 6 \\
0 & 0 & 1 & 4 & 6 \\
0 & 0 & 0 & 598 & 1007 \\
Total & & & $\mathbf{6 3 6}$ & $\mathbf{1 0 4 4}$ \\
\hline
\end{tabular}

iELISA: indirect ELISA; RBT: Rose Bengal Test; SAT: Slow Agglutination Test; 1: Positive; 0: Negative.

\section{Results}

\subsection{Data exploration}

The study was conducted initially between September 2007 and August 2008 for both sheep and goats and later between January 2010 and May 2010 for sheep. The mean age for goats was $1.6 \pm 0.06$ (mean \pm se) years ranging from 0.17 to 8 years whereas the mean body weight was $10.0 \pm 0.19$ (mean $\pm \mathrm{se}$ ) $\mathrm{kg}$ ranging from 2 to $30 \mathrm{~kg}$. About $95 \%$ of goats were of the Black Bengal breed and the rest were of Jamuanpari breed of origin. Sixty-six percent of the sampled goats were female. The median herd size of goats was 2 ranging from 1 to 18 . The mean age of sheep was $2.1 \pm 0.0 .04$ (mean \pm se) years ranging from 0.08 to 8 years whereas the mean body weight of was $14.6 \pm 0.15$ (mean $\pm \mathrm{se}$ ) $\mathrm{kg}$ ranging from 2 to $40 \mathrm{~kg}$. All sheep were of the indigenous type and $77 \%$ of them were female. The median herd size of sheep was 5 and ranged from 1 to 75 . The cross classified test results of the three serological tests on the 636 sera of goats and 1044 sera of sheep are shown in Table 2. Two (0.3\%) out of a total of 636 goats were positive for all three tests and $94 \%$ (598/636) were test negative. Similarly $8(0.8 \%)$ out of the total of 1044 sheep were positive for all three tests and $96.5 \%$ (1007/1044) were negative for all three tests (Table 2).
Table 4

Median posterior estimates of prevalence, sensitivity and specificity of iELISA, RBT and SAT for the diagnosis of brucellosis in goats in Bangladesh.

\begin{tabular}{llcl}
\hline Test & Variable & Median & $\begin{array}{l}\text { 95\% Credibility } \\
\text { interval }\end{array}$ \\
\hline \multirow{3}{*}{ iELISA } & Prevalence & 1.0 & $0.7,1.8$ \\
& Se & 92.9 & $87.3,98.3$ \\
Rose Bengal & Sp & 96.5 & $96.2,97.3$ \\
\multirow{3}{*}{ Slow Agglutination } & Se & 80.2 & $67.7,92.7$ \\
& Sp & 99.6 & $98.9,99.9$ \\
& Se & 57.1 & $31.7,91.4$ \\
& Sp & 99.3 & $98.4,99.8$ \\
\hline
\end{tabular}

\subsection{Model selection and posterior estimates}

The priors used in the Bayesian analyses were the same for the models for both goats and sheep. For the data for goats, the DIC for the conditional independence model was 26.09. None of the models with conditional dependence terms led to a significant reduction (of greater than 3 ) in DIC (Table 3 ). In addition, all the median estimates of the conditional correlations were close to 0.2 . The conditional independence model was therefore selected as a plausible model for the data for goats. The median estimates of the true prevalence of caprine brucellosis, sensitivity, and specificity of the three tests are summarized in Table 4 . The true prevalence of caprine brucellosis in Bangladesh was updated to $1 \%$ with $95 \%$ CrI of $0.7-1.8$. The highest sensitivity (92.8\% and 95\% CrI 87.3-98.3) with corresponding lowest specificity (96.5\% and 95\% CrI 96.2-97.3) was estimated for iELISA among goats. The specificity of both RBT and SAT were greater than $99.2 \%$ and the sensitivity of RBT was higher (80.2\%) than that of SAT (57.3\%) among goats.

For the data for sheep, all models that included the conditional covariance between RBT and SAT yielded significantly lower DICs (33.47-35.13) compared to the conditional independence model (52.3). Among these potential candidate models, the model with the lowest DIC and for which the magnitudes of the conditional covariance (between iELISA and RBT and between RBT and SAT) were considerably greater than 0.2 was selected. Based on the final model, the true prevalence of ovine brucellosis, sensitivity, specificity and dependence coefficients of the

\section{Table 3}

Comparison of model diagnostic parameters for conditional independence and different conditional dependence models used to estimate true prevalence of brucellosis in small ruminants and sensitivity and specificity of three diagnostic tests.

\begin{tabular}{|c|c|c|c|c|c|c|}
\hline \multirow[t]{2}{*}{ Models } & \multicolumn{3}{|l|}{ Goat } & \multicolumn{3}{|c|}{ Sheep } \\
\hline & Post. & $p D$ & DIC & Post. & $p D$ & DIC \\
\hline Conditional independence & 0.55 & 2.30 & 26.09 & 1.00 & 4.54 & 52.3 \\
\hline Conditional dependence (CD) between iELISA and RBT & 0.62 & 3.03 & 26.43 & 1.00 & 4.82 & 53.46 \\
\hline CD between iELISA and SAT & 0.63 & 3.10 & 27.30 & 1.00 & 5.03 & 52.87 \\
\hline CD between RBT and SAT & 0.61 & 3.33 & 27.60 & 0.49 & 5.19 & 34.10 \\
\hline CD between iELISA and RBT and between iELISA and SAT & 0.69 & 3.24 & 27.75 & 0.99 & 5.33 & 54.97 \\
\hline CD between iELISA and SAT and between RBT and SAT & 0.66 & 3.48 & 28.68 & 0.53 & 5.14 & 35.15 \\
\hline CD between iELISA and RBT and between RBT and SAT & 0.64 & 3.35 & 27.74 & 0.48 & 5.10 & 33.50 \\
\hline CD among all tests for infected animals & 0.57 & 3.02 & 25.65 & 0.99 & 4.44 & 46.88 \\
\hline CD among all tests for non-infected animals & 0.71 & 3.47 & 29.37 & 0.64 & 5.50 & 37.61 \\
\hline CD among all tests & 0.69 & 3.54 & 28.90 & 0.52 & 4.98 & 34.53 \\
\hline
\end{tabular}

iELISA: indirect ELISA; RBT: Rose Bengal Test; SAT: Slow Agglutination Test; Bold models were used to estimate prevalence and test characteristics for goat and sheep respectively; $p D$ : the number of parameters effectively estimated by the model; Post.: Post predictive $p$-value; DIC: Deviance Information Criterion. 
Table 5

Bayesian median posterior estimates of prevalence, conditional correlations, sensitivity and specificity of iELISA, RBT and SAT for the diagnosis of brucellosis in sheep in Bangladesh.

\begin{tabular}{|c|c|c|c|}
\hline Test & Variable & Median & 95\% Credibility interval \\
\hline & Prevalence & 1.2 & $0.6,2.2$ \\
\hline \multirow[t]{2}{*}{ iELISA } & $\mathrm{Se}$ & 92.0 & $87.2,98.2$ \\
\hline & $\mathrm{Sp}$ & 99.5 & $98.7,99.9$ \\
\hline \multirow[t]{2}{*}{ Rose Bengal } & $\mathrm{Se}$ & 82.8 & $68.1,92.9$ \\
\hline & Sp & 98.3 & $97.4,99.0$ \\
\hline \multirow[t]{2}{*}{ Slow Agglutination } & $\mathrm{Se}$ & 72.0 & $43.6,94.5$ \\
\hline & Sp & 98.6 & $97.8,99.2$ \\
\hline \multicolumn{4}{|l|}{ Dependence coefficient } \\
\hline Between iELISA and RBT among infected sheep & $\rho_{a 12}$ & 0.18 & $0.0,0.46$ \\
\hline Between RBT and SAT among infected sheep & $\rho_{a 23}$ & 0.53 & $0.32,0.72$ \\
\hline Between iELISA and RBT among non-infected sheep & $\rho_{b 12}$ & 0.29 & $-0.11,0.82$ \\
\hline Between RBT and SAT among non-infected sheep & $\rho_{b 23}$ & 0.40 & $-0.13,0.87$ \\
\hline
\end{tabular}

$\rho_{a i j}$ stands for the conditional correlation between test $i$ and test $j$ among infected subjects and $\rho_{b i j}$ stands for the conditional correlation between test $i$ and test $j$ among non-infected subjects.

three test combinations are as shown in Table 5. The true prevalence of ovine brucellosis in Bangladesh was estimated to be $1.2 \%$ with $95 \% \mathrm{CrI}$ of $0.6-2.2$. All the three tests were highly specific in sheep $(\geq 98.3 \%)$. The most sensitive test was the iELISA whereas the least sensitive was SAT. There was evidence of considerable conditional dependence between RBT and SAT among infected and non-infected sheep (Table 5).

\subsection{Sensitivity analyses results}

The results of the sensitivity analyses of the models for goats and sheep are shown in Tables 6 and 7 respectively.
The conditional independence model for goats and a conditional dependence model for sheep were used for the sensitivity analyses. The model diagnostic parameters indicated that the different set of priors yielded reasonable fit to the data. The true prevalence of caprine as well as ovine brucellosis and specificities of all three tests obtained from the different models of sensitivity analyses were similar to those of the selected models since their 95\% credibility intervals overlapped. Whereas the estimated specificities were the same as those of the selected models regardless of the set of priors used, the sensitivities were observed to vary and yielded wider confidence intervals. However, since the 95\% credibility intervals overlapped,

Table 6

Median posterior estimates of prevalence, sensitivity and specificity of iELISA, RBT and SAT based on a sensitivity analysis of the conditional independence model used to estimate true prevalence of caprine brucellosis and diagnostic test characteristics.

\begin{tabular}{|c|c|c|c|c|c|c|}
\hline Models \& tests & Post. & $p D$ & DIC & Prevalence (95\% CrI) & Sensitivity (95\% CrI) & Specificity (95\% CrI) \\
\hline UP for Prev and IP for Se and Sp & 0.55 & 2.89 & 25.92 & $0.6(0.2,1.6)$ & & \\
\hline ELISA & & & & & $93.0(87.3,98.3)$ & $96.5(96.2,97.3)$ \\
\hline RBT & & & & & $81.2(67.8,92.8)$ & $99.6(98.8,99.9)$ \\
\hline SAT & & & & & $60.1(32.1,92.9)$ & $99.3(98.4,99.8)$ \\
\hline UP for Prev and Sp and IP for Se & 0.40 & 3.65 & 25.32 & $0.6(0.2,1.5)$ & & \\
\hline ELISA & & & & & $93.0(87.3,98.3)$ & $95.3(93.5,96.8)$ \\
\hline RBT & & & & & $81.7(67.9,92.9)$ & $99.6(98.8,99.9)$ \\
\hline SAT & & & & & $62.1(32.3,93.5)$ & $99.3(98.4,99.8)$ \\
\hline IP for Prev and UP for Se and Sp & 0.57 & 3.42 & 27.97 & $1.1(0.7,3.3)$ & & \\
\hline ELISA & & & & & $69.6(23.9,98.5)$ & $95.5(93.6,97.2)$ \\
\hline RBT & & & & & $62.5(15.3,98.1)$ & $99.7(98.9,100)$ \\
\hline SAT & & & & & $46.0(10.2,90.8)$ & $99.3(98.5,99.9)$ \\
\hline IP for Prev and Se and UP for Sp & 0.39 & 3.06 & 25.57 & $0.9(0.7,1.7)$ & & \\
\hline ELISA & & & & & $92.8(87.3,98.3)$ & $95.4(93.5,96.9)$ \\
\hline RBT & & & & & $80.9(67.7,92.8)$ & $99.6(98.9,99.9)$ \\
\hline SAT & & & & & $59.0(31.9,92.1)$ & $99.3(98.4,99.8)$ \\
\hline IP for Prev and Sp and UP for Se & 0.70 & 2.07 & 28.03 & $1.3(0.7,5.0)$ & & \\
\hline ELISA & & & & & $71.1(26.1,98.5)$ & $96.6(96.2,98.0)$ \\
\hline RBT & & & & & $51.1(10.2,97.0)$ & $99.7(98.9,100)$ \\
\hline SAT & & & & & $37.5(6.9,87.1)$ & $99.3(98.5,99.9)$ \\
\hline $\begin{array}{l}\text { Perturbation example: } 10 \% \text { decrease of } \\
\text { lower limits of Se and Sp }\end{array}$ & 0.39 & 3.13 & 25.69 & $0.9(0.7,1.8)$ & & \\
\hline ELISA & & & & & $88.0(77.6,98.1)$ & $95.4(93.5,96.8)$ \\
\hline RBT & & & & & $85.3(77.4,93.0)$ & $99.6(98.9,99.9)$ \\
\hline SAT & & & & & $56.6(23.4,91.9)$ & $99.3(98.4,99.8)$ \\
\hline
\end{tabular}

UP: uniform prior; IP: informative prior; Prev: prevalence; Se: sensitivities; Sp: specificities; CrI: credibility interval; iELISA: indirect ELISA; RBT: Rose Bengal Test; SAT: Slow Agglutination Test; Post.: Post. pred. $p$-value; $p D$ : the number of parameters effectively estimated by the model; DIC: Deviance Information Criterion. 
Table 7

Median posterior estimates of prevalence, sensitivity and specificity of iELISA, RBT and SAT based on a sensitivity analysis of a conditional dependence model used to estimate true prevalence of ovine brucellosis and diagnostic test characteristics.

\begin{tabular}{|c|c|c|c|c|c|c|}
\hline Models \& tests & Post. & $p D$ & DIC & Prevalence (95\% CrI) & Sensitivity (95\% CrI) & Specificity $((95 \% \mathrm{CrI}))$ \\
\hline UP for Prev and IP for Se and Sp & 0.48 & 5.09 & 33.49 & $1.2(0.6,2.2)$ & & \\
\hline ELISA & & & & & $92.1(87.2,98.2)$ & $99.5(98.7,99.9)$ \\
\hline RBT & & & & & $82.8(68.1,92.9)$ & $98.3(97.4,99.0)$ \\
\hline SAT & & & & & $72.2(43.6 .4,94.5)$ & $98.6(97.8,99.2)$ \\
\hline UP for Prev and Sp and IP for Se & 0.49 & 5.18 & 33.70 & $1.2(0.5,2.2)$ & & \\
\hline ELISA & & & & & $92.1(87.2,98.2)$ & $99.5(98.7,99.9)$ \\
\hline RBT & & & & & $82.7(68.1,92.9)$ & $98.3(97.3,99.0)$ \\
\hline SAT & & & & & $72.0(43.6,94.5)$ & $98.5(97.7,99.2)$ \\
\hline IP for Prev and UP for Se and Sp & 0.49 & 4.43 & 31.84 & $2.1(0.8,4.3)$ & & \\
\hline ELISA & & & & & $52.7(25.1,94.3)$ & $99.5(98.7,100)$ \\
\hline RBT & & & & & $75.0(37.0,99.0)$ & $98.8(97.6,99.9)$ \\
\hline SAT & & & & & $66.4(35.2,96.6)$ & $99.1(98.0,99.9)$ \\
\hline IP for Prev and Se and UP for Sp & 0.49 & 5.21 & 33.77 & $1.2(0.5,2.2)$ & & \\
\hline ELISA & & & & & $92.1(87.2,98.2)$ & $99.5(98.7,99.9)$ \\
\hline RBT & & & & & $82.8(68.1,92.9)$ & $98.3(97.3,99.0)$ \\
\hline SAT & & & & & $72.0(43.7,94.5)$ & $98.5(97.7,99.2)$ \\
\hline IP for Prev and Sp and UP Se & 0.49 & 4.41 & 31.79 & $2.1(0.8,4.3)$ & & \\
\hline ELISA & & & & & $52.7(25.0,94.3)$ & $99.5(98.7,100)$ \\
\hline RBT & & & & & $75.2(37.2,98.9)$ & $98.8(97.7,99.9)$ \\
\hline SAT & & & & & $65.5(35.3,96.7)$ & $99.1(99.1,99.9)$ \\
\hline $\begin{array}{l}\text { Perturbation example: } 10 \% \text { decrease of } \\
\text { lower limits of Se and Sp }\end{array}$ & 0.50 & 5.11 & 33.45 & $1.3(0.6,2.5)$ & & \\
\hline ELISA & & & & & $85.5(77.4,97.7)$ & $99.5(98.7,100)$ \\
\hline RBT & & & & & $80.1(59.6,92.8)$ & $98.3(97.4,99.1)$ \\
\hline SAT & & & & & $70.5(41.4,94.3)$ & $98.6(97.7,99.3)$ \\
\hline
\end{tabular}

UP: uniform prior; IP: informative prior; Prev: prevalence; Se: sensitivities; Sp: specificities; CrI: credibility interval; iELISA: indirect ELISA; RBT: Rose Bengal Test; SAT: Slow Agglutination Test; Post.: Post. pred. $p$-value; $p D$ : the number of parameters effectively estimated by the model; DIC: Deviance Information Criterion.

the observed differences were not statistically important (Tables 6 and 7). For example, the true median prevalence of goats and sheep were $1.0 \%$ (95\% CrI: $0.7-1.8 \%$ ) and $1.2 \%$ (95\% CrI: $0.6-2.2 \%$ ) respectively and the ranges of the median prevalence obtained in sensitivity analyses respectively for goat and sheep ranged from $0.6-5 \%$ to $0.5-4.3 \%$ respectively. Decreasing the lower limits of all the prior intervals by $10 \%$ led to only slight and statistically unimportant changes in the estimated parameter values and their 95\% Cr Intervals in the models for both goats and sheep.

\section{Discussion}

In this study, the true prevalence and diagnostic test characteristics for brucellosis in goats and sheep were determined using a Bayesian analysis framework. More than $90 \%$ of the goats in the country were of the Black Bengal breed. The study area had the highest density of small ruminants $\left(>300 \mathrm{~km}^{2}\right.$ ) in Bangladesh (Anonymous, 2005) and about $95 \%$ of the goats sampled were of the Black Bengal breed. The sheep sample covered almost all the divisions except Khulna division of Bangladesh. The breed of sampled sheep was indigenous which is predominant all over Bangladesh (Bhuiyan, 2006). However, a study based on micro-satellite markers by Khan et al. (2009) described Garole sheep of Satkhira district (within Khulna division) as an independent sheep breed in Bangladesh. So, the prevalence estimated in this study is based on a representative sample of goats and sheep and would therefore be applicable to the goats and sheep (except Khulna division) populations of Bangladesh. About $1 \%$ of goats and $1.2 \%$ of sheep of Bangladesh were found to be serologically positive for brucellosis. The prevalence of brucellosis in goats and sheep are within the range of previously reported apparent prevalence. However, through this study we obtained the true prevalence along with their true probability interval (credibility interval contains the true parameter with 95\% certainty) (Mustafa, 1984; Rahman et al., 1988; Enøe et al., 2000; Amin, 2003; Uddin, 2006; Rahman et al., 2011a,b). The relatively higher seroprevalence in sheep may be due to the relatively larger herd sizes of sheep compared to goats in Bangladesh. Larger herd sizes have been reported to be significantly associated with brucellosis seropositivity among livestock (Mikolon et al., 1998; Kabagambe et al., 2001; Solorio-Rivera et al., 2007).

In Bangladesh, among livestock farmers about $49 \%$ rear small ruminants either alone or with large ruminants and about 53\% farmers who share same premises with animals are goat owners (Rahman et al., 2012). As small ruminants come in very close contact with humans, brucellosis in goats and sheep should be controlled with the highest priority in order to control this zoonosis in humans. In Bangladesh, goats are a very valuable asset especially for the poor people. They mature sexually quite early, at 6-8 months of age, and breed around the year. They kid twice a year and meat and skin obtained from the Black Bengal are of excellent quality and fetch high prices, even in the local market. Sheep of Bangladesh are also as prolific 
as goats. Small ruminants with clinical signs suggestive of brucellosis (abortion, retained fetal membrane, anestrous, etc.) are usually sold and eventually slaughtered by butchers. Moreover, around 15 million goats are slaughtered annually and of them about $40 \%$ are performed during the annual festival of Eid-ul-Azha (Anonymous, 2007). It has been shown that the longer infected animals are in contact with the rest of the herd, the greater the number of seropositive animals (Radostits et al., 2000). Large scale slaughtering of small ruminants for meat consumption may reduce the number of infected animals in the population. These factors may be responsible for low prevalence in goats and sheep of Bangladesh. In such an intermediate (1-5\%) prevalence scenario of small ruminants brucellosis in Bangladesh, eradication can be achieved mainly by test and slaughter policy. However, pre-requisites for undertaking eradication programs such as: good organization of farmers and veterinary services, the implementation of strict movement control measures, an efficient identification system of the animals, no chance of sharing common grazing places and availability of financial resources are not yet at hand. The complete understanding of the disease including the species and biovars of Brucella involved in small ruminants should also be known for planning control programs (Anonymous, 2006; Minas, 2006).

In this study, the performance of iELISA and RBT were relatively better than that of SAT in goats and sheep. The specificity estimates of SAT and RBT were very similar. The sensitivities of iELISA and RBT were similar in both sheep and goats. However, the specificity of iELISA (95.5\%) was slightly lower in goats compared to sheep whereas that of RBT was slightly lower in sheep compared to goats. The increased specificity of iELISA in sheep was due to the higher cut-off values than that of goats. The sensitivity and specificity of iELISA estimated were in accordance with results from other studies (Abuharfeil and Abo-Shehada, 1998; Burriel et al., 2004). The sensitivity of RBT in goats and sheep were $80.2 \%$ and $82.8 \%$ respectively even though the specificity of RBT in both goats and sheep was more than $98 \%$. The estimated sensitivity and specificity of RBT were coherent with findings from previous studies (Nielsen et al., 2004; Ramirez-Pfeiffer et al., 2008). The sensitivity and specificity of SAT in goats and sheep were $57.1 \%, 99.3 \%$ and $72.0 \%, 98.6 \%$ respectively. The sensitivity and specificity of SAT were also in accordance with results from other studies (Baum et al., 1995; Gupta et al., 2010). The iELISA was the most sensitive and specific test explaining the fact that acutely infected animals were less common in the population. The serological response observed in this study includes both $B$. abortus and $B$. melitensis infections but excludes $B$. ovis as its antibody does not react with antigens prepared by SLPS. The proportion of goats and sheep infected with $B$. abortus and B. melitensis in Bangladesh is not yet known. But B. abortus was detected from goat milk using real time PCR assay (unpublished data). Among the three tests none was sensitive and specific enough to be used alone for the diagnosis of caprine brucellosis in Bangladesh. In the model for goats, the hypothesis of conditional dependence among the three tests was not important. This might have been due to small and sometimes zero cell frequencies observed for goats. In sheep, considerable conditional dependence between iELISA and RBT and between RBT and SAT among infected as well as non-infected sheep were observed. The iELISA is a quantitative test which detects only IgG, SAT quantifies both IgM and IgG (but mainly IgM) and RBT qualitatively detects both IgM and IgG (Christopher et al., 2010; Godfroid et al., 2010; Di'az et al., 2011). The conditional correlation between RBT and SAT for sheep may be explained by the similarity of the type of antibody detected. The weaker conditional correlation between iELISA and RBT among infected as well as non-infected sheep may be explained by the fact that RBT also partially detects IgG. The sensitivity analysis of the conditional independence model for goats and a conditional dependence model for sheep revealed that the results can be considered to be robust. Slight differences in prevalence and sensitivities were observed but the differences were not statistically important as the credibility intervals of the estimates overlapped with those of the prevalence and sensitivities of the serological tests in the chosen models for goats and sheep (Tables 4-7).

\section{Conclusion}

This study is the first to evaluate the accuracy of brucellosis diagnostic tests among sheep and goats in Bangladesh considering conditional dependence between the diagnostic tests. An intermediate level of true prevalence of brucellosis among goats and sheep respectively was estimated. Such low prevalence will allow test and slaughter policy to control this zoonosis in small ruminants. There was considerable conditional dependence between iELISA and RBT and between RBT and SAT implying that a combination of the three serological tests may be a plausible choice unless other tests with very high sensitivity and specificity are validated. In multiple test validation, conditional dependence should not be ignored when the tests are in fact conditionally dependent.

\section{Acknowledgements}

This study was supported by the Belgian Directorate General for Development Cooperation(DGDC). The authors are grateful to the Institute of Tropical Medicine (ITM) for logistic and technical support, the University of Liege for scientific guidance \& the staff of CODA-CERVA for technical assistance.

\section{Appendix A and B. Supplementary data}

Supplementary data associated with this article can be found, in the online version, at http://dx.doi.org/10.1016/ j.prevetmed.2012.11.029.

\section{References}

Abuharfeil, N., Abo-Shehada, M.N., 1998. A comparison between three serological tests for Brucella melitensis infection in sheep. Turk. J. Vet Anim. Sci. 22, 119-122.

Adel, A., Saegerman, C., Speybroeck, N., Praet Victor, B., Deken, R.D. Soukehal, A., Berkvens, D., 2010. Canine leishmaniasis in Algeria: true prevalence and diagnostic test characteristics in groups of dogs of different functional type. Vet. Parasitol. 172 (3-4), 204-213. 
Alton, G.G., Jones, L.M., Angus, R.D., Verger, J.M., 1988. Techniques for the Brucellosis Laboratory. INRA, Paris, France, pp. 112-189.

Amin, K.M.R., 2003. Serological epidemiology of bovine and caprine brucellosis. MS Thesis. Department of Microbiology and Hygiene, Bangladesh Agricultural University, Mymensingh-2202, Bangladesh.

Amin, M.R., 2006. Goat genetic resources in Bangladesh. <http://wwwnaweb.iaea.org/nafa/aph/stories/2006-black-bengal.html>. (accessed October 2010).

Anonymous, 1986. Joint FAO: WHO Expert Committee on Brucellosis. Sixth Report. World Health Organization Technical Report Series No. 740. World Health Organization, Geneva.

Anonymous, 2005. Livestock sector brief of Bangladesh. Food and Agriculture Organization of the United Nations. <http://www.fao. org/ag/againfo/resources/en/publications/sector_briefs/lsb_BGD.pdf> (accessed October 2010).

Anonymous, 2006. Brucellosis in human and animals. Food and Agriculture Organization. <http://www.who.int/csr/resources/publications/ Brucellosis.pdf $>$ (accessed October 2010).

Anonymous, 2007. National livestock development policy. Ministry of Fisheries and Livestock, Government of the People's Republic of Bangladesh. <http://www.dls.gov.bd/files/Livestock_Policy_Final.pdf> (accessed October 2010)

Baum, M., Zamir, O., Bergman-Rios, R., Katz, E., Beider, Z., Cohen, A., Banai, M., 1995. Comparative evaluation of microagglutination test and serum agglutination test as supplementary diagnostic methods for brucellosis. J. Clin. Microbiol. 33 (8), 2166.

BBS, 2004. The Bangladesh Census of Agriculture (Rural) 1996, Structure of Agricultural Holdings and Livestock Population, vol. 1. Bangladesh Bureau of Statistics, Dhaka, vol. 1.

Berkvens, D., Speybroek, N., Praet, N., Adel, A., Lesaffre, E., 2006. Estimating disease prevalence in a Bayesian framework using probabilistic constraints. Epidemiology 17, 145-153.

Bhuiyan, A.K.F.H., 2006. Livestock genetic resources in Bangladesh: Preservation and Management. In: International Conference on Livestock Services, Chinese Academy of Agricultural Science (CAAS), Beijing, China, 16-20 April.

Blasco, J.M., Garin-Bastuji, B., Marín, C., Gerbier, G., Fanlo, J., Jiménez De Bagués, M., Cau, C., 1994. Efficacy of different Rose Bengal and Complement Fixation antigens for the diagnosis of Brucella melitensis in sheep and goats. Vet. Rec. 134, 415-420.

Branscum, A.J., Gardner, I.A., Wagner, B.A., McInturff, P.S., Salman, M.D., 2005. Effect of diagnostic testing error on intracluster correlation coefficient estimation. Prev. Vet. Med. 69, 63-75.

Burriel, A.R., Christodoulopoulos, G., Bisias, G., Fthenakis, G.C., 2004 Comparison of fluorescence polarization assay, indirect ELISA and competitive ELISA methods for diagnosis of Brucella melitensisinfection in small ruminants. Small Ruminant Res. 54, 243-247.

Christopher, S., Umapathy, B.L., Ravikumar, K.L., 2010. Brucellosis: review on the recent trends in pathogenicity and laboratory diagnosis. J. Lab. Physicians 2 (2), 55.

Dendukuri, N., Joseph, L., 2001. Bayesian approaches to modeling the conditional dependence between multiple diagnostic tests. Biometrics 7 , 158-167.

Dı'az, R., Casanova, A., Ariza, J., Moriyo'n, I., 2011. The Rose Bengal Test in human Brucellosis: a neglected test for the diagnosis of a neglected disease. PLoS Negl. Trop. Dis. 5 (4), e950, http://dx.doi.org/10.1371/journal.pntd.0000950.

EFSA-Q-2006. The EFSA Journal (2006) 432, 1-44 Scientific Opinion on "Performance of Brucellosis Diagnostic Methods for Bovines, Sheep, and Goats", pp. 110-111.

Enøe, C., Georgiadis, M.P., Johnson, W.O., 2000. Estimation of sensitivity and specificity of diagnostic tests and disease prevalence when the true disease is unknown. Prev. Vet. Med. 45, 61-81.

European Commission (EC), 2001. Brucellosis in sheep and goats (Brucella melitensis) SANCO.C.2/AH/R23/2001. <http://www.europa.eu. int/comm/food/fs/sc/scah/out59_en.pdf> (accessed October 2010).

Ferris, R.A., Schoenbaum, M.A., Crawford, R.P., 1995. Comparison of serological tests and bacteriologic culture for detection of brucellosis in swine from naturally infected herds. J. Am. Vet. Med. Assoc. 207, 1332-1333.

Franco, M.P., Mulder, M., Gilman, R.H., Smits, H.L., 2007. Human brucellosis. Lancet Infect. Dis. 7, 775-786.

Gardner, I.A., Stryhn, H., Lind, P., Collins, M.T., 2000. Conditional dependence between tests affects the diagnosis and surveillance of animal diseases. Prev. Vet. Med. 45, 107-122.

Garin, B., Trap, D., Gaumont, R., 1985. Assessment of EDTA seroagglutination test for the diagnosis of bovine brucellosis. Vet. Rec. 117, 444-445.

Gelman, A.E., Rubin, D.B., 1992. Inference from iterative simulation using multiple sequences. Stat. Sci. 7 (4), 457-472.
Georgiadis, M.P., Johnson, W.O., Gardner, I.A., Singh, R., 2003. Correlation-adjusted estimation of sensitivity and specificity of two diagnostic tests. J.R. Stat. Soc. Ser. C: Appl. Stat. 52 (1), 63-76.

Godfroid, J., Cloeckaert, A., Liautard, J.P., Kohler, S., Fretin, D., Walravens, K., Garin-Bastuji, B., Letesson, J.J., 2005. From the discovery of the Malta fever's agent to the discovery of a marine mammal reservoir, brucellosis has continuously been a re-emerging zoonosis. Vet. Res. 36, 313-326.

Godfroid, J., Nielsen, K., Saegerman, C., 2010. Diagnosis of brucellosis in livestock and wildlife. Croat. Med. J. 51, 296-305.

Godfroid, J., Saegerman, C., Wellemans, V., Walravens, K., Letesson, J.J., Tibor, A., Mc Milan, A., Spencer, S., Sanna, M., Bakker, D., Pouillot, R., Grain-Bastuji, B., 2002. How to substantiate eradication of bovine brucellosis when a specific serological reactions occur in the course of brucellosis testing. Vet. Microbiol. 90, 461-477.

Gupta, V.K., Kumari, R., Vohra, J., Singh, S.V., Vihan, V.S., 2010. Comparative evaluation of recombinant BP26 protein for serological diagnosis of Brucella melitensis infection in goats. Small Ruminant Res. 93, 19-125.

Haley, C., Wagner, B., Puvanendiran, S., Abrahante, J., Murtaugh, M.P., 2011. Diagnostic performance measures of ELISA and quantitative PCR tests for porcine circovirus type 2 exposure using Bayesian latent class analysis. Prev. Vet. Med. 101 (1), 79-88.

Harbord, R.M., Whiting, P., 2009. Metandi: meta-analysis of diagnostic accuracy using hierarchical logistic regression. Stata J. 9 (2), 211-229.

Jones, G., Johnson, W.O., Hanson, T.E., Christensen, R., 2010. Identifiability of models for multiple diagnostic testing in the absence of a gold standard. Biometrics 66 (3), 855-863.

Kabagambe, E.K., Elzer, P.H., Geaghan, J.P., Opuda-Asibo, J., Scholl, D.T., Miller, J.E., 2001. Risk factors for Brucella seropositivity in goat herds in eastern and western Uganda. Prev. Vet. Med. 52, 91-108.

Kelly, D., Smith, C., 2011. Bayesian Inference for Probabilistic Risk Assessment: A Practitioner's Guidebook. Springer, London.

Khan, M.Y.A., Husain, S.S., Alam, M.R., Teneva, A., Han, J.L., Faruque, M.O., 2009. Genetic relationships in different sheep populations of Bangladesh based on microsatellite markers. J. Bangladesh Agril. Univ. 7 (2), 291-294.

Kostoulas, P., Leontides, L., Enře, C., Billinis, C., Florou, M., Sofia, M., 2006. Bayesian estimation of sensitivity and specificity of serum ELISA and faecal culture for diagnosis of paratuberculosis in Greek dairy sheep and goats. Prev. Vet. Med. 76, 56-73.

Limet, J.N., Kerkhofs, P., Wijffels, R., Dekeyser, P., 1988. Le diagnostic serologique de la brucellose bovine par ELISA. Ann. Med. Vet. 132, 565-575.

Mainar-Jaime, R.C., Muñoz, P.M., De Miguel, M.J., Grilló, M.J., Marín, C.M., Moriyón, I., Blasco, J.M., 2005. Specificity dependence between serological tests for diagnosing bovine brucellosis in Brucella-free farms showing false positive serological reactions due to Yersinia enterocolitica 0:9. Can. Vet. J. 46, 913-916.

Mikolon, A.B., Gardner, I.A., Hernandez De Anda, J., Hietala, S.K., 1998. Risk factors for brucellosis seropositivity of goat herds in the Mexicalli Valley of Baja California. Mexico. Prev. Vet. Med. 37, 185-195.

Minas, A., Stournara, A., Minas, M., Papaioannou, A., Krikelis, V., Tselepidis, S., 2005. Validation of fluorescence polarization assay (FPA) and comparison with other tests used for diagnosis of $B$. melitensis infection in sheep. Vet. Microbiol. 111 (3), 211-221.

Minas, A., 2006. Control and eradication of brucellosis in small ruminants. Small Ruminants Res. 62, 101-107.

Minas, A., Stournara, A., Christodoulopoulos, G., Katsoulos, P.D., 2008. Validation of a competitive ELISA for diagnosis of Brucella melitensis infection in sheep and goats. The Vet. J. 177, 411-417.

Mustafa, A.H., 1984. Brucella antibodies in the sera of domestic livestock in Bangladesh. Trop. Anim. Health Prod. 16, 212.

Nérette, P., Hammell, L., Dohoo, I., Gardner, I., 2008. Evaluation of testing strategies for infectious salmon anaemia and implications for surveillance and control programs. Aquaculture 280 (1-4), 53-59.

Nielsen, K., 2002. Diagnosis of brucellosis by serology. Vet. Microbiol. 90, 447-459.

Nielsen, K., Gall, D., Smith, P., Balsevicius, S., Garrido, F., Ferrer, M.D., Biancifiori, F., Dajer, A., Luna, E., Samartino, L., Bermudez, R., Moreno, F., Renteria, T., Corral, A., 2004. Comparison of serological tests for the detection of ovine and caprine antibody to Brucella melitensis. Rev. Sci. Technol 23 (3), 979-987.

Nielsen, K., Gall, D., Smith, P., Bermudez, R., Moreno, F., Renteria, Ruiz, T.A. Aparicio, L., Vazquez, S., Dajer, A., Luna, E., Samartino, L., Halbert, G., 2005. Evaluation of serological tests for detection of caprine antibody to Brucella melitensis. Small Ruminants Res. 56, 253-258.

Ntzoufras, I., 2011. Bayesian Modeling Using WinBugs. Wiley Series in Computational Statistics, Hoboken, USA (Chapter 2.4.3). 
OIE (World Organization for Animal Health), 2008. Chapter 2.4.3, Bovine brucellosis. In: Manual of Diagnostic Tests and Vaccines for Terrestrial Animals, 6th ed. OIE, Paris, France, pp. 624-659.

Praud, A., Gimenez, O., Zanella, G., Dufour, B., Pozzi, N., Antras, V., Meyer, L., Garin-Bastuji, B., 2012. Estimation of sensitivity and specificity of five serological tests for the diagnosis of porcine brucellosis. Prev. Vet. Med. 104, 94-100.

Radostits, O.M., Gay, C.C., Blood, D.C., Hinchcliff, K.W., 2000. Chapter 18, Diseases associated with bacteria-III. In: Veterinary Medicine: A Textbook of the Disease of Cattle, Sheep, Pigs, Goats and Horses, 9th ed. W.B. Saunders Company Ltd., Sydney, pp. 963-994.

Rahman, A.K.M.A., Berkvens, D., Fretin, D., Saegerman, C., Ahmed, M.U. Muhammad, N., Hossain, A., Abatih, E., 2012. Seroprevalence and risk factors for brucellosis in a high-risk group of individuals in Bangladesh. Foodborne Pathog. Dis. 9 (3), 190-197.

Rahman, M.M., Haque, M., Rahman, M.A., 1988. Seroprevalence of caprine and human brucellosis in some selected areas of Bangladesh. Bangladesh Vet. J. 22, 85-92.

Rahman, M.S., Faruk, M.O., Her, M., Kim, J.Y., Kang, S.I., Jung, S.C., 2011a. Prevalence of brucellosis in ruminants in Bangladesh. Vet. Med (Praha) 56 (8), 379-385.

Rahman, M.S., Hahsin, F.A., Ahasan, M.S., Her, M., Kim, J.Y., Kang, S.I., Jung, S.C., 2011b. Brucellosis in sheep and goat of Bogra and Mymensingh districts of Bangladesh. Korean J. Vet. Res. 51 (4), 277-280.
Ramirez-Pfeiffer, C., Diaz-Aparicio, E., Gomez-Flores, R., Rodriguez-Padilla C., Morales-Loredo, A., Alvarez-Ojeda, G., 2008. Use of the Brucella melitensis native hapten to diagnose brucellosis in goats by a rapid, simple, and specific fluorescence polarization assay. Clin. Vaccine Immunol. 15 (6), 911-915.

Shey-Njila, O., Nya, D.E., Zoli, P.A., Walravens, K., Godfroid, J., Geerts, S 2005. Serological survey of bovine brucellosis in Cameroon. Rev. Elev. Méd. Vét. 58 (3), 139-143.

Solorio-Rivera, J.L., Segura-Correa, J.C., Sanchez-Gil, L.G., 2007. Seroprevalence and risk factors for brucellosis of goats in herds of Michoacan. Mexico. Prev. Vet. Med. 82, 282-290.

Spiegelhalter, D.J., Best, N.G., Carlin, B.R., Van der Linde, A., 2002. Bayesian measures of model complexity and fit. J. R. Stat. Soc. Ser. B: Stat. Methodol. 64, 583-616.

Spiegelhalter, D.J., Thomas, A., Best, N.G., Lunn, D., 2003. WinBUGS Version 1. 4 User Manual. MRC Biostatistics Unit, Cambridge.

Uddin, M.J., 2006. Survey of brucellosis in sheep and goats of Bangladesh. MS Thesis. Department of Medicine, Bangladesh Agricultural University, Mymensingh-2202, Bangladesh.

Van Tonder, E., Herr, S., Bishop, G., Bosman, P., 1994. Brucella ovis infection. In: Coetzer, J.A.W., Thomson, G.R., Tunstin, R.C. (Eds.), Infectious Diseases of Livestock with Special Reference to Southern Africa. Oxford University Press, Cape Town, pp. 1067-1071.

Vacek, P.M., 1985. The effect of conditional dependence on the evaluation of diagnostic tests. Biometrics 41, 959-968. 